\section{Osteopathic research: Growth and development}

When Mervin E. Meck, D.O., served as president of the $\mathrm{AOA}$, as he went around the country speaking and listening to the profession, he observed the need for more succinct information concerning the beginnings, growth, and present status of osteopathic medical research. The profession in general, and the students in particular, had neither a comprehensive knowledge of the early beginnings of research under osteopathic auspices, nor information about its stage of development. The book, "Osteopathic research: Growth and development," is the result of several years' work by a committee, appointed by Dr. Meck, of distinguished osteopathic researchers. Its publication was made possible through generous financial support of Smith Kline \& French Laboratories and Coroon and Black of Illinois, Inc., the insurance brokers for the AOA.

Dr. Meck was impressed with the interest of the students in our medical colleges, relative to research done, being done, and/or contemplated. In the foreword of the book, he makes this pertinent comment: “...in my travels, I heard questions from students and interns, from physicians, and from many people outside the osteopathic profession who sought factual information about the foundations of osteopathic theory and practice. It became evident to me that the vast wealth of osteopathic research material was not available in a form that could be recovered with ease."

We do not pretend that the book is a definitive history on osteopathic research; rather, we feel that it provides a good overview of the profession's efforts in this area.

Wilbur V. Cole, D.O., authored chapters on the "Historical basis for osteopathic theory and practice," and "Osteopathic research: Anatomical and histopathological evidence."

Myron C. Beal, D.O., wrote chapters on "Biomechanics: A foundation for osteopathic theory and practice," and "Clinical research," and Albert F. Kelso, Ph.D., wrote a chapter on "Physiology." A chapter titled "The status and future of osteopathic research" was coauthored by Albert F. Kelso, Ph.D., and Alexandra A. Townsend, D.O.

The book is moderately priced at $\$ 11.00$ (hardcover) and $\$ 9.00$ (softcover). Prepaid orders can be placed with the American Osteopathic Association, 212 East Ohio Street, Chicago, Illinois 60611-3269, Attention: Order Department.

We are confident that it will contribute much to your knowledge of osteopathic research and its importance.

GEORGE W. NORTHUP, D.O., FAAO

\section{Research and the continued development of osteopathic medicine}

The bulk of advances in medical research have come from the laboratories in osteopathic and allopathic medical schools. Physicians trained in research skills, and often holding the Ph.D. degree, have provided the core faculty in medical schools for teaching and for biomedical research. As physicians, these teacher-investigators have been effective in bridging the gap between the basic sciences and clinical practice.

It is imperative that the colleges of osteopathic medicine support and receive support for continued and expanded research efforts. In his paper, "Clinical research in osteopathic medicine," Gilbert E. D'Alonzo, D.O., writes, "It is hard to imagine maintaining intellectual vitality and advanced educational programs without research. The constant turnout of young, fresh, enthusiastic minds allows research to progress most effectively when melded with advanced training... The quality of health care is conditioned largely by operational or applied medical research." The paper is featured in the Special Communications Section of this issue of JAOA and begins on page 440/113.

Medical research has always been a part of the osteopathic medical profession. Early research in the colleges of osteopathic medicine was predominantly clinical and was directed by osteopathic physicians, with a few notable exceptions. ${ }^{1}$ More recently, however, as reported by D'Alonzo, the trend has been towards nonclinicians as primary investigators. In 492 research studies performed 